Article

\title{
Migration and Health-Freedom of Movement and Social Benefits for Chinese Migrant Workers
}

\author{
Fengxian Qiu ${ }^{1} \mathbb{D}$, Jing Liu ${ }^{2, *}$ and Heying Jenny Zhan ${ }^{3}$ \\ 1 Department of Social Work, School of Law, Anhui Normal University, Wuhu 241003, China; \\ qiufengxian01@ahnu.edu.cn \\ 2 Department of Labor and Social Security, School of Public Administration, Zhejiang University of Finance \\ and Economics, Hangzhou 310018, China \\ 3 Department of Sociology, College of Arts \& Sciences, Georgia State University, Atlanta, GA 30302, USA; \\ hzhan@gsu.edu \\ * Correspondence: jliu65@zufe.edu.cn
}

check for updates

Citation: Qiu, F.; Liu, J.; Zhan, H.J. Migration and Health-Freedom of Movement and Social Benefits for Chinese Migrant Workers.

Sustainability 2021, 13, 12371. https:/ / doi.org/10.3390/su132212371

Received: 8 October 2021

Accepted: 8 November 2021

Published: 9 November 2021

Publisher's Note: MDPI stays neutral with regard to jurisdictional claims in published maps and institutional affiliations.

Copyright: (c) 2021 by the authors. Licensee MDPI, Basel, Switzerland. This article is an open access article distributed under the terms and conditions of the Creative Commons Attribution (CC BY) license (https:// creativecommons.org/licenses/by/ $4.0 /)$.

\begin{abstract}
This study utilized the concept of social right to understand factors affecting migrant workers' health and healthcare in China. Using mixed methods, this study integrated findings from a survey of 817 migrant workers and a follow-up study of 30 intensive interviews to present an in-depth understanding of cumulative disadvantage of health and healthcare of rural-to-urban migrant workers. Our quantitative results indicated that migrant workers with no more than 5 years of working experience and having a good relationship with employers were $65 \%$ and $72.8 \%$ more likely to report good self-rated health as compared to their counterparts; those with workrelated injury experience and low income were $41.6 \%$ and $53.6 \%$ less likely to report good self-rated health. Qualitative findings revealed the social contexts of the cumulative effect of the length of work experience and fear of medical cost on migrant workers' declining health. Even though the participation rate for health insurance in China is reported to be over $99 \%$, the lack of portability in health insurance and different reimbursement rates in health care access are structural barriers in health-seeking behaviors among Chinese migrant workers and in establishing sustainability in China's healthcare system. This study adds to the literature by delineating the process of the unequal access to social rights in general, healthcare in particular as the major explanation for migrant workers' poor health beyond the surface of China's universal healthcare.
\end{abstract}

Keywords: migrant workers; health; healthcare; medical cost; health insurance; healthcare portability

\section{Introduction}

Rural-to-urban migrant workers are known as the "floating population" in China, emphasizing the characteristics of their transient and unstable social status in urban areas. In 2019, there were roughly 300 million migrant workers in China, accounting for 30\% of China's total workforce [1]. As a marginalized group, they suffer from poverty [2], poor housing quality [3,4], and dangerous working conditions [5,6], all of which result in severe health consequences. In 2003, China started the "new rural cooperative medical insurance system (NRCMIS)" [7]. It is an attempt to make health care accessible to China's 600 million rural residents. As of 2013, the enrollment rate for the NRCMIS had reached over $99 \%$ in China [8]. This high participation rate is a significant achievement of China's national healthcare. Yet, this health insurance does not ensure the freedom of movement for China's rural residents working in urban areas (migrant workers). When a migrant worker becomes sick in an urban workplace, she/he needs to return to home village for diagnosis and treatment to be reimbursed. Although extensive previous studies, as mentioned above, have pointed out that migrant workers suffer from poverty, poor housing quality, dangerous working conditions, few have utilized both quantitative and qualitative data to elucidate the process of migrant workers' cumulative disadvantage in health and healthcare. 
This paper digs deeper beyond the $99 \%$ healthcare insurance enrollment; thus, adds to the existing literature by unveiling the structural problems of China's urban/rural binary healthcare systems. Using both qualitative and quantitative data, we enabled an in-depth understanding of Chinese migrant workers' health and healthcare. While quantitative data provided an essential understanding for factors influencing migrant workers health and well-being; qualitative data helped contextualize the realities of healthcare practices in contemporary China. In the process, we shed light on the social rights, social stratification systems, and cumulative disadvantage in health as well as the access and management of healthcare in China.

\subsection{Social Right and Social Harmony}

The concept of social right has been widely discussed and implemented in social policies among social democratic Nordic countries and in the European Union (EU). Initiated by T.H. Marshall, social right is fundamentally the share of social benefits among citizens in the same nation in education, pension, health care, and a decent standard of living in a given society [9]. With the fall of the Berlin Wall, the freedom of movement of goods, services, capital, and people, demanded access to cross-border healthcare. In 2008, the European Union proposed the "Directive on the application of patients' rights in cross-border healthcare." [10]. Under this law, "when the citizens of a Member State travel outside their countries, they are entitled to receive health care should they need it, and have it reimbursed by their home (national) authority" [11]. Regardless of their differences, "healthcare is the responsibility of the member states and the EHIC has ensured interactions of people (staff and patients), goods, services, and freedom of movement across borders" (Mossialos et al., 2010, p. 4).

Social right has been used interchangeably with the concept of social harmony in China. Constructing a "harmonious society" had been the slogan under the former President $\mathrm{Hu}$ Jintao. After 2012, President Xi Jinping has put a great emphasis on "Social Harmony." The connotations of "harmony" in these two social contexts have changed. Ge and Huang [12] differentiated the concept of "harmonious society" from "social harmony" as a core social value in these two different eras. While "Constructing a harmonious society" focused mainly on a peaceful and lawful society, "social harmony" as a core social value emphasized social integration and a greater share of national wealth. In 2017, the central government put "developing rural China" as an important task in its Community Party agenda. Qiu [13] argued, to develop or vitalize rural China, the key was to break the rural and urban binary divide to allow an equal share of public services and social benefits. Though not using the word "social rights," clearly, there have been open discussions of the greater share of social benefits among all Chinese citizens. Of all social benefits, healthcare is at the core.

\subsection{An Overview of the Healthcare System in Rural China}

The initial stage of China's rural healthcare system was operated under its collectivization system in the 1950s [14], also known as the rural cooperative medical system (RCMS). Under RCMS, farmers with backgrounds in traditional Chinese medicine, were trained with basic modern medical skills and served as the primary healthcare providers, known as the "barefoot doctors" in rural areas. They were mostly part-time doctors who also bore farming responsibilities. The collective welfare funds of local communes constituted a major source of funding for the RCMS [15]; meanwhile, farmers also contributed roughly $0.5 \%$ to $2 \%$ of their annual income to the funding [16]. This system had provided Chinese farmers basic access to primary healthcare before the $1980^{\prime} \mathrm{s}$ economic reform. However, as China transformed from a collective economy to a market economy in the 1980s, a major breakdown of the initial RCMS occurred. The collapse of the communes resulted in severe disruptions of the public funding sources and thus significantly reduced farmers' participation in the RCMS. By 1984, Chinese villages covered by the RCMS had dropped from $90 \%$ to $4.8 \%$ [16]. Most rural residents had lost basic medical care security, and the self-financed medical system had become dominant in rural China [17]. 
The new rural cooperative medical insurance system (NRCMIS) was introduced in 2003, emphasizing the joint financial efforts of the central and local governments, villages, and rural residents to meet rural residents' basic healthcare needs. Participation in the NRCMIS was not mandated, but it was highly encouraged. Funds were first collected from rural participants at village level and then transferred to the town, city, and provincial governments [18]. Poor families who were qualified for the waiver program were automatically enrolled in the program without any fees [19]. Participants who participated in the program received no less than $10 \mathrm{RMB}$ a year from the local government to compensate their healthcare expenses, but it required their contribution of no less than 10 RMB a year [7]. The central government subsidized an additional 10 RMB a year for participants in the less developed regions on top of the local government's subsidies and personal contributions. This effort was meant to protect rural residents from poverty caused by possible massive hospitalization expenses. However, outpatient treatments, medicine, and minor illness have barely been covered [20]. This has limited the actual benefits that participants could receive. Secondly, based on the regulations of the NRCMS, medical expenses can only be reimbursed at the best rate if rural residents use health services in where their hukou (residential registration) is located [21]. The reimbursement rate decreased significantly with higher copay if the health services were used outside of one's residential registration area [21]. Therefore, migrant workers in various urban locations would have to return to their hometown to have such costs reimbursed at the best rate, but most of them can't afford to miss work because of the potential threat of losing their job or income.

In 2016, The NRCMIS was combined with the urban resident medical insurance system and was collectively named the urban and rural residents' medical insurance system [22]. This recent change has allowed rural migrant workers to seek medical treatment in urban locations within the same province. It is, however, not portable outside the province. The reimbursement rates continue to differ vastly based on the locations of hukou and medical treatments received. The current non-portable feature and the discrepancy in reimbursement rates of the Chinese healthcare system is believed to be the result of the ongoing disparities in levels of economic development and income in China between costal and interior, urban and rural regions of China [23]. These disparities translate into differing healthcare insurance rate and coverages for urban and rural, coastal and interior regions [24].

\subsection{The Social Insurance System in China}

Work-related injury insurance, old-age pension, health insurance, childbirth insurance, and unemployment insurance constitute the main body of China's social insurance system [25]. They are often employment-based and offered as a whole package to workers as part of the employment benefits through an employment contract. Workers who are covered by the system enjoy financial compensations/reimbursement for work-related injuries, old age security, illness, childbirth, and unemployment. Workers are generally required to make monthly contributions to their accounts with their employers. However, migrant workers were often not offered such contracts, because they mostly worked in jobs with high turnover rates in small or private businesses [26]. Some migrant workers would also prefer working without such contracts to increase their take-home income [25].

\subsection{Cumulative Disadvantage in Health}

Although Chinese migrant workers work and reside in urban areas, they do not enjoy the urban social benefits as their birthplaces were in rural areas. China's current healthcare system encourages people to seek healthcare services at local hospitals where their hukou are registered; in return, they receive maximized healthcare cost reimbursement. However, most rural-to-urban migrant workers have migrated out of their rural hometowns for better job opportunities. Therefore, when having health issues, their options are either going to doctors in urban areas where they work but paying most/all costs out of pocket or going back to rural hometown for a better healthcare cost reimbursement rate but with a potential 
consequence of losing jobs. Consequently, migrant workers delay their necessary medical treatments; this delayed healthcare has led many minor illnesses to become major health crises, resulting in a vicious cycle of a cumulative disadvantage in health.

\subsection{Demographic Factors and Self-Rated Health}

Self-rated health is a global, reliable, and easy to administer measure of an individual's overall health [27]. It was shown to associate with demographic indicators in a large body of the previous health literature. Older age, being male, having lower educational attainment, and working in dangerous occupations were associated with poor SRH [28]. Health had been found to decline as people age [29]. Male workers were more likely to report poorer health because they were more likely to engage in occupations with higher risks, such as construction work, and have unhealthy lifestyles, such as smoking and drinking [30]. Lower educational attainment was associated with a lower level of health knowledge [29], and a greater likelihood of working in physically straining and dangerous jobs [31]. These demographic factors have provided a basic understanding of health disparities in the Chinese migrant population.

\subsection{Employment Experience and Self-Rated Health}

Employment experiences constitute the main source of social determinants of health among Chinese migrant workers besides demographic variables. For example, workrelated injury experiences [31] and longer years of working in the physically demanding work environment [32] led to poorer health. Such experiences could impact health by directly causing physical and mental harm, and indirectly, through migrant worker's limited access to local public health services and health insurance when in need of medical help $[5,6]$.

Conversely, positive employment experiences, such as having pleasant relationships with colleagues and employers, promoted good health in employment settings. In a previous study focusing on Chinese migrant workers' work and lives, Meng and Li [33] found that having pleasant social relationships was essential for migrant workers' health. Understandably, pleasant relationships help migrant workers foster a sense of belonging and provide migrant workers some social support when needed. A positive work environment may help them battle life obstacles and integrate into cities.

\subsection{Income and Self-Rated Health}

Higher income promoted health in the Chinese migrant population [32,34]. Before migrating into urban areas, migrant workers' living expenses were minimal because houses were self-owned, and food was mainly produced by their lands. However, living expenses had dramatically increased after they emigrated to cities due to the costly rent, daily groceries, and transportations in cities. Therefore, those with higher incomes were more likely to afford urban living expenses, had better nutrition, housing, health-related investment (such as health insurance and fitness), and health management. Previous research found that people with lower incomes were also significantly less likely to utilize healthcare services than their richer counterparts $[35,36]$. In urban areas where they work, migrant workers in China are not eligible for urban healthcare benefits. Purchasing commercial health insurance is not affordable and feasible. Thus, not surprisingly, only very few migrant workers with high-income level can afford to use medical services in urban areas.

Based on our review of the previous literature and our understanding of the current social context, we raised three overarching research questions. First, how do migrant workers' length of work experience, work-related injury experience, and positive work experience affect their self-rated health? Second, does higher income indicate better selfrated health? The third research question is contextual. We inquire how healthcare practices are related to their self-rated health. This is a qualitative question that can only be addressed 
with qualitative data. With our overarching research questions, we present the following conceptual model of our study (see Figure 1).

\section{Employment Experience \\ --Length of work (longer work experience) \\ --Work related injuries \\ --Poor relationship with employers and Colleagues}

Financial Status

--Lower Monthly income

Poor Self-rated Health

No Portable health Insurance

--No to minimal health maintenance

--Fear of medical cost without health insurance

Figure 1. The Conceptual Model of Chinese Migrant Workers' Cumulative Disadvantage in Health.

\section{Methods}

This study utilized both quantitative and qualitative data for the understanding of migrant workers' health and healthcare. The study design and instruments were approved by the Institutional Review Board of the host university of the author. The following sections first present our quantitative sample and methods, then present our qualitative data to provide contextualized understandings.

\subsection{Quantitative Dataset and Sample}

The quantitative data of this paper came from the Survey of Chinese Migrant Worker's Sustainable Livelihood. This is a cross-sectional dataset designed to provide information on the Chinese migrant workers' health status, financial well-being, and retirement planning. Survey questions assessing migrant workers' health and migration experiences were adopted from the Survey of Rural Floating Population [37] and the Chinese Migrant Worker Survey [38] respectively. In the Survey of Rural Floating Population, Du [37] had chosen self-rated health as a major health outcome, because migrant workers generally have limited access to urban health services, therefore, physician's assessment of health may not be accessible to most migrant workers, nor researchers. Using self-rated health as a health measure better enables researchers' access to the study population. Data collection was conducted in 2018 in three Chinese emigration provinces, Anhui, Henan, and Sichuan, by a group of trained researchers at a university in central China. The following including criteria were used while determining the eligibility of study participants: age range was set at 45 and above; residency status was set by legal rural residency in the above provinces; participants had at least one year of work experience as a migrant worker. Random sampling was not feasible since over $50 \%$ of the working-age population in these provinces were working as migrants outside their home village. Therefore, data collection was conducted at respondents' home during holidays or around the Chinese New Year when migrant workers were most likely to have returned home. Informed consent from all respondents was obtained before the data collection. A total of 1200 migrant workers were initially identified. 117 did not complete the survey. After excluding those who did not provide valid answers for our study variables, our final sample size was 817 . 


\subsection{Measurements}

Self-rated health is the dependent variable of this study. Respondents were asked to rate their health as either good $(=1)$ or poor $(=0)$. Whether or not migrant workers had health insurance was a question asked to all respondents. However, everyone in the study reported that they had bought health insurance in the rural hometown. Considering its small variance, we decided not to include this variable in the analysis. The length of employment was coded into 5 years or below and 6 to 9 years, with 10 years and above as the reference category. Work-rated injury experience was measured by a question asking whether they have experienced any work-related injury (yes $=1$; no $=0$ ). Relationships with colleagues and employers are two variables which were measured by two separate questions asking migrant workers' self-perceived relationships with colleagues and employers (good relationship $=1$; poor $=0$ ). Income was measured in 3 categories. Respondents were asked, "what is your monthly income at present or at most recent job"? Respondents could choose from $1=3000$ RMB (\$425) or below, 2 = 3001-5000 RMB (\$425 to $\$ 714)$, and $3=5000 \mathrm{RMB}(\$ 714+)$ and above. Based on China's urban average pay standard, below 3000 RMB was coded as low income, 3001-5000 RMB was coded as medium income, with high income (5000 RMB+) as the reference category.

Respondents' demographic characteristics, including age, gender, educational attainment, and work type, were used to reduce the chances of spurious statistical inferences in this paper. Age was measured in years. Gender was coded as male $(=1)$, with the female $(=0)$ as the reference category. Educational attainment was categorized as elementary school, middle school, and high school and above. Work type was coded as workers, such as construction or factory workers $(=1)$, with other work types, such as service jobs $(=0)$ as the reference category.

\subsection{Statistical Analysis}

Two nested binary logistic regression models were estimated using SPSS version 25 to test the effect of migration experience on Chinese migrant workers' self-rated health. Model 1 contained respondents' demographic variables, length of employment, workrelated injury experience, relationship with colleagues and employers. Model 2 further added respondents' income into the equation.

\subsection{Qualitative Data Collection and Methods of Data Analyses}

To gain an additional in-depth understanding of migrant workers' health and healthcare, we did a follow-up interview with 30 migrant workers in 2020 after the survey. Applying the concept of theoretical saturation in our interviewing sampling [39], we focused on three factors shown important in quantitative analysis: work length and workrelated health issues, healthcare-seeking experience in urban areas, and income in relation to health. When we asked interviewees' work-related health issues, we focused on their types of work and length of work in relation to their health. After reaching a theoretical saturation, i.e., no additional new information can be drawn from the interviewees, we added an additional factor, such as health-seeking experience in urban areas, into our study. To understand how migrant workers handled their health problems and work-related injuries, we sought to find migrant workers who had experienced work-related injuries and health problems. These methods have allowed us a more profound and targeted understanding of the relationship between migrant workers' work and health management experiences in urban locations in relation to their health.

All interviews were audio-recorded, and field notes were taken on the same day. Most interviews lasted from 30 to $60 \mathrm{~min}$. Before the interview, each participant was informed about the research, data collection method, and the procedure of protecting participants information. The confidentiality of interviews was strictly maintained. Pseudonyms were used to protect interviewees' confidentiality. All interviews took place in a public space mutually agreed upon between the interviewee and interviewer. IRB approvals were obtained from the university in China as well as the collaborating university in the U.S. 
All recorded tapes were transcribed into Chinese, and the transcriptions along with field notes were logged into Words for analyses. Data analyses were performed in Chinese by one key senior researcher, following a modified grounded theory approach [39]. Once the data pool was set, the analytical process began with line-by-line open coding of concepts, following the three guiding research questions. For example, categories that emerged from open coding include fear of cost, fear of illness, have no illness, have only minor aches and pains, etc. After the initial coding procedure, axial coding was applied to find the interconnection between categories; and understand how categories were contextualized and perhaps intertwined with one another [39]. With axial coding, the relationships between categories were identified. For example, the reason for not seeking health care in urban areas was linked to their fear of high cost, the lack of portability in health care, and the fear of loss of income or job. During this process, a relation diagram was created to visualize and denote the interactions between categories. Finally, related categories were combined to form a larger theoretical scheme, where core categories were generated [39]. The notion of cumulative disadvantage emerged, which served as the core category in this research.

\section{Results}

\subsection{Quantitative Results}

As shown in Table 1, most respondents were male (74.3\%), workers $(61.7 \%)$, with middle school certificates $(50.4 \%)$. The gender distribution is consistent with the overall trend of gender distribution among the rural-to-urban migrant workers. The traditional gender and family roles have resulted in most female farmers staying at home and taking on the homemaking and caregiving roles instead of out-migrating for jobs [40,41]. The average age was 52.8, with a standard deviation of 5.9. Among all, 51.3\% reported good self-rated health, $24.7 \%$ reported having work-related injury experience. Over half of the respondents had at least 10 years of work experience as migrant workers, followed by $23.4 \%$ reporting having 5 years or below and $16.8 \%$ having 6 to 9 years of work experience. Most respondents (60.8\%) reported having good relationships with colleagues, but only $43.9 \%$ reported having good relationships with employers. Most of our respondents were low $(42.6 \%)$ and medium level $(38.3 \%)$ income earners, only $19.1 \%$ reported earning a high income.

Bivariate correlations were performed among all variables used to check for possible multi-collinearity issues (Table available upon request). Significant correlations were found between self-rated health and all variables used in the analysis, except for respondents gender, work type, and relationship with colleagues. Either non-significant correlations or weak to medium correlations were observed among all the independent and control variables, indicating that multi-collinearity is not an issue for this study.

Table 2 shows the odds ratio and the standard error for the effects of employment experience and monthly income on self-rated health, net of the influence of respondent's demographic variables. As shown in model 1, the length of employment was a significant predictor for self-rated health among Chinese migrant workers. Individuals who had less than 5 years of working experience were $44.7 \%$ more likely to report good self-rated health than those with more than 10 years of working experience, net of the influence of all other variables. This indicates the potential deteriorating effect of longer employment experience on migrant worker's health. Having work-related injury experience significantly threatened migrant worker's health. Individuals who had such experiences were $42.7 \%$ less likely to report good self-rated health than those who did not have such experience. A good relationship with employer as a type of positive work experience significantly promoted migrant worker's health. Those reported having good relationship with employer were $77.7 \%$ more likely to report good self-rated health as compared to their counterparts who reported poor relationship with employers. However, no significant relationship was found between good relationship with colleagues and self-rated health in our quantitative results. 
Table 1. Descriptive statistics.

\begin{tabular}{|c|c|c|}
\hline & $\%(\mathbf{N})$ & M(SD) \\
\hline \multicolumn{3}{|l|}{ Dependent Variable } \\
\hline \multicolumn{3}{|l|}{ Self-rated health } \\
\hline Good & $51.3 \%(419)$ & \\
\hline Poor & $48.7 \%(398)$ & \\
\hline \multicolumn{3}{|l|}{ Independent Variables } \\
\hline \multicolumn{3}{|l|}{ Length of employment } \\
\hline 5 years or below & $23.4 \%(191)$ & \\
\hline $6-9$ years & $16.8 \%(137)$ & \\
\hline 10 years and above & $59.9 \%(489)$ & \\
\hline \multicolumn{3}{|l|}{ Work-related injury experience } \\
\hline Yes & $24.7 \%(202)$ & \\
\hline No & $75.3 \%(615)$ & \\
\hline \multicolumn{3}{|c|}{ Self-perceived relationship with colleagues } \\
\hline Good & $60.8 \%(497)$ & \\
\hline Poor & $39.2 \%(320)$ & \\
\hline \multicolumn{3}{|c|}{ Self-perceived relationship with employer } \\
\hline Good & $43.9 \%(359)$ & \\
\hline Poor & $56.1 \%(458)$ & \\
\hline \multicolumn{3}{|l|}{ Monthly income } \\
\hline Low & $42.6 \%(348$ & \\
\hline Medium & $38.3 \%(313)$ & \\
\hline High & $19.1 \%(156)$ & \\
\hline \multicolumn{3}{|l|}{ Demographic Variables } \\
\hline Age $^{1}$ & & $52.8(5.9)$ \\
\hline \multicolumn{3}{|l|}{ Gender } \\
\hline Male & $74.3 \%(607)$ & \\
\hline Female & $25.7 \%(210)$ & \\
\hline \multicolumn{3}{|l|}{ Education } \\
\hline Elementary school or below & $35.9 \%(293)$ & \\
\hline Middle school & $50.4 \%(412)$ & \\
\hline High school or above & $14.6 \%(112)$ & \\
\hline \multicolumn{3}{|l|}{ Work type } \\
\hline Workers & $61.7 \%(504)$ & \\
\hline Other work type & $38.3 \%(313)$ & \\
\hline
\end{tabular}

Notes: $\mathrm{N}=817 .{ }^{1}$ Range $=45-77$. 
Table 2. Binary logistic regression models predicting self-rated health $(n=817)$.

\begin{tabular}{|c|c|c|}
\hline & Model 1 & Model 2 \\
\hline \multicolumn{3}{|l|}{ Demographic Variables } \\
\hline Age & $0.968(0.013) *$ & $0.972(.013) *$ \\
\hline Male (ref. = female) & $1.321(0.182)$ & $1.213(.185)$ \\
\hline \multicolumn{3}{|l|}{ Education (ref. = high school and above) } \\
\hline Elementary & $0.560(0.235) *$ & $0.627(.239)$ \\
\hline Middle school & $0.844(0.224)$ & $0.937(.227)$ \\
\hline Workers (ref. = other work type) & $1.162(0.163)$ & $1.229(.167)$ \\
\hline \multicolumn{3}{|l|}{ Independent Variables } \\
\hline \multicolumn{3}{|l|}{$\begin{array}{l}\text { Length of employment (ref. = } 10 \text { years } \\
\text { and above) }\end{array}$} \\
\hline 5 years or below & $1.447(0.181) *$ & $1.650(.187)^{* *}$ \\
\hline $6-9$ years & $0.990(0.201)$ & $1.039(.203)$ \\
\hline Work-related injury experience (ref. = no) & $0.572(0.171)^{* *}$ & $0.584(.174)^{* *}$ \\
\hline Good relationship with colleagues (ref. = poor) & $1.021(0.158)$ & $1.023(.160)$ \\
\hline Good relationship with employer (ref. $=$ poor) & $1.777(0.155)^{* * *}$ & $1.728(.157)^{* *}$ \\
\hline \multicolumn{3}{|l|}{ Income (ref. = high) } \\
\hline Low & & $0.464(.214)^{* * *}$ \\
\hline Medium & & $0.576(.213) *$ \\
\hline Nagelkerke R Square & 0.082 & 0.102 \\
\hline $\mathrm{N}$ & 817 & 817 \\
\hline
\end{tabular}

Model 2 indicates that a higher level of monthly income promoted migrant worker's health. Individuals with low and medium-level income were $53.6 \%$ and $42.4 \%$ less likely to report good self-rated health, respectively, compared to those with high income after holding all employment experience and demographic variables constant. After adding monthly income to the model, the significant relationship between educational attainment and self-rated health had been explained away, and most previously significant relationships had been attenuated to some degree, suggesting the powerful role of income in affecting human health. However, it is noteworthy that income also served as a suppressor in the relationship between the length of employment and self-rated health. Respondents who had no more than 5 years of working experience were now $65 \%$ more likely to report good self-rated health as compared to their counterparts who had more than 10 years of working experience after taking monthly income into account.

Quantitative findings gave us understandings for factors influencing migrant workers health and wellbeing; qualitative research findings helped contextualize the realities of health care practices in contemporary China. How did work experience, length of work, employer-employee relationship, and income play out in lived experiences? Qualitative data had enriched our understanding.

\subsection{Qualitative Results}

Qualitative results are presented in three core categories generated by the interview data analyses. They help provide the social context of healthcare practices as well as offer the reasons behind quantitative findings. 


\subsection{Cumulative Disadvantage in Health}

In-depth interviews with migrant workers had allowed us to see that the participation of NRCMIS was nearly $100 \%$ after excluding the few (3 out of 30) who had already participated in the urban health insurance. Only those three who had urban healthcare reported having health check-ups. When asking if they had any illness, most migrant workers would say, "I have only minor aches and pains, no major illness." Due to the fear of high medical cost, most migrant workers would either self-treat an illness by buying over-the-counter drugs or simply avoid going to the hospital altogether.

Ms. Cao, aged 52, was an on-site cook for a construction crew in Wuhu. It had been her 12th year working as a migrant worker. When asked if she had ever suffered any illness during her years working in the city, she replied:

I suffer from lower back pain constantly, but I seldom went to see a doctor or visited a hospital. If the pain is not going to kill me, there is no point for seeing a doctor. I remember one time, the pain was very intense, so I went to the hospital. The doctor told me I had an infection; I had to take an IV to treat the infection. Since it was just an infection, I realized that I could just buy some antibiotics to treat the infection myself next time. (Case 6)

Many antibiotics are available as over-the-counter drugs in China. Patients buying antibiotics to self-treat an infection was a commonplace. Similarly, Mr. Zhang, aged 52, reported having severe back pain. He had been working in urban areas for 26 years. He also had NRCMIS, but no local health insurance at the workplace. He suffered from back pain for years, which he simply ignored and accepted as a part of his life.

For years, I dared not enter a hospital. When I went into a hospital, my heart would beat like a drum. I had no idea how much money it would cost me. I feared that the little money I earned would all be thrown away in the hospital. Last year, my back pain was quite intense; I couldn't bear it anymore. To receive treatment, I had to have a co-worker accompany me home, taking a long-distance bus to visit the local rural clinic for primary care. With the doctor's referral from the rural clinic, I was then sent to the county-level hospital. There, I was diagnosed to have lumbar tuberculosis. I was hospitalized for some time for treatment. Since it is not the type of illness that requires surgery, I had to pay more attention to self-care and health maintenance. So, I figured, I would just start working again. Without work, I had no income. (Case 16)

Similarly, the fear of medical costs and high hospitalization fees had delayed Ms. Kim's treatment. She worked in Shanghai as a janitor in 2018. She felt dizzy every day in early 2018, and her calves and legs were swollen. For several months, she went to small clinics seeking consultation.

At first, nurses in a nearby clinic thought she had high blood pressure. After testing, it was denied. Then, she did a blood test for diabetes, no diagnosis was confirmed. She dragged on until the end of the year when she returned to her home village. Her husband insisted on taking her to a doctor in the county hospital after seeing her become so thin and miserable. With proper attention and tests, she was diagnosed with hyperthyroidism.

(Case 30)

As shown, rural migrant workers, though they worked and resided in urban areas, generally had no medical insurance in cities. When illness stroke, they had to return to their rural villages to receive treatment. The lack of portability in medical insurance for migrant workers was a major obstacle in their pursuit of medical treatment. The fear of high medical costs further prevented migrant workers from seeking preventive care or proper medical attention. Not until a crisis stroke did a migrant worker sought to see a doctor. In such a case, they might have to travel a long distance to return rural homes to obtain affordable medical care. This lack of portability and high cost of medical care in cities have collectively contributed to their cumulative disadvantage in healthcare. Minor aches and pains, when 
not treated due to fear of cost and lack of medical care portability, eventually turned into major illnesses, as shown in the stories told by these migrant workers.

\subsection{Work-Related Health Problems}

During the years working as migrant workers, having work-related accidents has dramatically changed migrant workers' health and well-being. Before 2008, accidental insurance was not required by the government; employers, especially small construction companies, would not purchase this insurance for workers. When accidents happened, workers were usually paid the minimum medical care, but compensation for loss of income was generally not paid. Most workers never even heard about this insurance. Mr. Zhu, aged 50, working as a carpenter in a housing development company, provided the following details when he was asked about his work-related injury and insurance. He said:

I did have a fall at work. This fall had given me constant back pain. My health is not that good nowadays. It is connected to that fall. I never heard about injury insurance. I also have had friends who were injured at work. They never had any accidental insurance either. Some bosses are nice; they take you to the hospital for treatment. Others don't care. You have to pay for medical treatment out of your pocket. I have never heard about unemployment insurance either. You see, I have to work, even if I have constant pain. When the pain is intense, I take a break. But if I don't work, I would have no income. (Case 11)

Mr. Yao, aged 56, working in an electric machinery factory. About 8 years ago, he worked in a factory outside of his home province. One day, while working, his electric tape dropped. He bent down to pick up the tape, and his arm was accidentally caught into the electric machine. He was carried to the hospital. The company paid over 700,000 yuan for medical treatment.

After coming out of the hospital, I was still recovering, could not work. So, I went to ask for some money to survive. The boss gave me 300 to 500 yuan each time, a total of 10 times or so. When I could start moving my arm, I stopped asking him for living expenses. I never heard about work-related accidental insurance. (Case 18)

Mr. Wu was 65 years old, came from Anhui province, but worked in Shanghai for years. In 2012, he started to see red dots on his skin. He thought it was just skin rash or allergy. So, he went to a clinic for antibiotic treatment. After a week of receiving IV antibiotic treatment, there was no improvement; instead, a fever broke out.

So, I had to go to a local hospital in Shanghai for a diagnosis. The doctor told me that I had lupus erythematosus. It is often caused by pesticide or high chemical contact. I was working in a factory making fabric for clothing. I handled chemical dye on a daily basis. The dye smelled bad; it affected my health over the years. It has been 7 to 8 years since the diagnosis, I had developed a kidney complication due to this disease. I have to go to the hospital once every month for treatment. The treatment has costed between 700,000 to $800,000$ yuan ( $\$ 100 \mathrm{~K}$ to $120 \mathrm{~K})$, roughly 200,000 to 300,000 yuan were out of my own pocket. Reimbursement rate is roughly half if inside the province. In shanghai, I only got a $20 \%$ to $30 \%$ reimbursement rate. (Case 28 )

As shown, work-related injuries were directly related to accumulated health problems. The longer migrant workers worked in cities, the more likely they were to face health challenges and, sometimes, more severe health problems. The lack of portability of healthcare, the low reimbursement rate when treatment occurred outside one's county or province directly related to migrant workers' reluctance to seek treatment. Having a good relationship with the boss could mean that the worker, once injured, may receive some living expenses.

These contextualized findings from the qualitative research reveal that non-portable healthcare delayed migrant workers' adequate and timely treatment, thus negatively affected their health. Healthcare context is complicated. Sometimes, only by providing 
qualitative details can readers understand the nuances beyond $100 \%$ participation of healthcare among migrant workers.

\subsection{Higher Monthly Income Means Better Health}

Several migrant workers shared their pleasant work experience and promising retirement future. Mr. Zhang, 45 years old, came from Anhui province, but worked in Zhejiang Province for over 27 years when being interviewed (East coast, near Shanghai). He worked in the field of communication technology. His monthly income was 8000 yuan.

I have bought all five insurances through the workplace: health, retirement, unemployment, injury, and reproductive health. My work unit offers very good benefits to employees. Every year, the work unit offers an annual health check-up. You know, health check-ups are very important. Many minor illnesses, if you don't pay attention, may turn into major health problems. If we can discover a minor illness and treat it early, we can stay healthy. I have also put aside money for my retirement. (Case 23)

The field of communicative technology has been a very profitable and rapidly growing industry in China. Good benefits in his company had given Mr. Zhang a promising future in both his good health and a good retirement.

Mr. Wang, aged 49, had worked outside his home province for 27 years. He was promoted to a managerial position in a furniture factory by the time of this interview. His monthly salary was 15,000 yuan, about three times as much as an average migrant worker. When asked about his health and health insurance, he replied cheerfully:

My company bought us health and retirement insurances. The work unit also offers an annual health check-up for us. If I don't have good health, I would have nothing. I have also put aside some money to prepare for my old age. I have to rely on myself in old age. Once I have saved a good pension, I would have no fear in old age. (Case 26)

Only three migrant workers among the 30 interviewed had urban healthcare, thus were able to afford health check-ups. Ninety percent of migrant workers never had a preventive health check-up while working in urban areas. Among the interviewees, most expressed fear of medical cost as an explanation for not seeking medical treatment at the time of illness. Eventually, a minor illness had turned into a major health catastrophe.

\section{Discussion}

Both quantitative and qualitative findings in this study showed that work-related injuries experience and length of employment directly affected migrant workers' health. Our quantitative and qualitative findings showed that longer working years and dangerous work experiences had caused many migrant workers to have debilitating health problems. Most migrant workers never had a health check-up, saw a doctor, or visited a hospital while working in urban areas. Most simply said "We only have minor aches and pains, no real illness". They stayed away from hospitals because of their fear of the high cost of medical bills. Consequently, these minor illnesses turned into a major health crisis.

Having a good relationship with the employer, on the other hand, was positively associated with better self-rated health, as shown in quantitative data analysis. Pleasant relationships with the employer may increase the employer's willingness to purchase better healthcare or pay for living expenses in case of injury or loss of wages for migrant workers. Such social capital promotes migrant workers' better health by having annual check-ups and a stronger sense of health security.

Our quantitative findings also showed that having higher level of income promoted self-rated health because higher income allowed migrant workers to buy better health insurance and put aside money for future uncertainties. It is particularly important to note that monthly income also served as a suppressor in the relationship between the length of employment and self-rated health. Even though longer work experience deteriorates migrant workers' health, it also comes with opportunities for increased income because of their improved skills. However, when we hold the income level constant, the potential 
benefit of working longer years has disappeared, thus enhancing the negative effect of longer work-years on migrant workers' health. Even though this cross-sectional study is unable to determine a causal relationship between income and health, its findings add to the existing literature supporting the correlation between income and health [32,34]. Future longitudinal study designs may better tease out the interaction between income and health.

The originality of this paper is demonstrated by its strength of combining both quantitative and qualitative data to reveal a full picture of rural-to-urban migrant workers' health and healthcare experience. The two structural policy barriers facing migrant workers are the lack of portable healthcare benefit and continued social stratification of urban/rural divide in healthcare systems. The social context of China's urban/rural divide and implicit inequalities in the unequal access to healthcare for migrant workers cannot be understood by simple quantifiable numbers. Our qualitative findings enabled readers to hear and see the inequalities in health and healthcare as experienced by migrant workers and played out in the urban/rural healthcare systems. These inequalities are structural barriers challenging the sustainability of China's healthcare system.

\section{Conclusions}

China has made unprecedented progress in its alleviation of absolute poverty. By 2017, 800 million Chinese people were out of poverty [42]. In the process of building a harmonious socialist China, as shown in the 17th National Congress of the Chinese Communist Party, the central government sets the goal that "all citizens have the rights to receive education, remuneration, employment, medical care, and housing" [42]. The share of social wealth and social benefit has been brought to the center of the national conversation and government agenda. The healthcare insurance participation rate is reported to be nearly universal since 2013 [8]. Yet, the actual implementation of these social welfare policies in general, healthcare in particular, appears to be still lagging based on this 2018-2020 field study. This study contributes to the existing literature by delineating the ongoing major differences and inequalities in access to and reimbursement rates for health care in rural and urban China. For 300 million rural migrant workers who work in urban China, these inequalities deter their health-seeking behaviors, and create cumulative disadvantage for their health and healthcare access. The EU has conquered the differences in languages, religions, medical systems, and governments to allow citizens from different nations to carry a European Health Insurance Card to access healthcare across borders. China will have adequate resources to overcome the urban-rural divide in its healthcare system as well, especially under its banner of constructing a harmonious society. The key appears to lie in, to what extent, this access to "healthcare for all" can be addressed accordingly in the Chinese social context. Even though the poverty rate has decreased by 800 million, the gap between the rich and poor has increased dramatically in China. In 2018, the Gini Index coefficient showed its score at $51 \%$ [43]. China is now positioning itself to be the second greatest economy in the world. Will it follow the Neo-Liberal model of the U.S. in its development of social welfare? Or will it follow the social democratic model of the Nordic or EU to make social rights as one of its core values for a post-industrial, urbanized, and aging China in its effort to improve the equal share of social benefits between its rural and urban residents? For future policy directions, social policies such as imposing a payroll tax for all employers and employees for universal healthcare, making healthcare portable with equal reimbursement rate between urban and rural, from one province to another, are urgently needed in the process of building a harmonious society in China.

This study was based on a convenient sample of 817 migrant workers in three major emigrant provinces in China. It is a cross-sectional study, which to some extent has limited our chance to explore the reverse causality between respondents' SES and health due to the lack of the respondents' health information before 2018. Meanwhile, interpretation of the findings implying causality should take caution. A longitudinal study may yield a better understanding of changing health at different points of aging and migrant workers' experience. Second, respondents are from three major provinces with large numbers 
of emigrants. Different provinces may have different policies or policy implementation processes. What happened to migrant workers in Anhui may not apply to migrant workers in Hunan. Third, all respondents in our quantitative and qualitative data were rural-tourban migrant workers, thus has limited our chance to investigate and make comparisons with urban-to-urban migrant workers. Fourth, due to the data availability, self-rated health in this research was assessed as a binary variable for better statistical inference, therefore, it, to some extent, limited our chance to see the differences between individuals with different levels of health status. However, since nearly $50 \%$ respondents in our quantitative dataset have reported poor self-rated health, we thus believe that our results are insightful in understanding factors promote or hinder them to have good self-rated health at the first place.

Despite of its limitations, this study has the strength of combining the quantitative and qualitative findings to tell a full story of the lived experiences of migration, health, and healthcare. Specifically, the quantitative results revealed that migrant workers' income and employment experience such as length of work, work-related injury, and relationship with employers affected their health; the qualitative results further shed light on the cumulative effect of the length of work experience and fear of medical cost on migrant workers' declining health. The lack of portability in health insurance and different reimbursement rates in health care access are structural barriers in health-seeking behaviors among Chinese migrant workers. This study adds contextualized understanding of social inequalities of healthcare access beneath the surface of China's universal health care. Its insight applies not only to China but other countries that have large numbers of migrant laborers who have no portable health care.

Author Contributions: Conceptualization, H.J.Z., J.L. and F.Q.; methodology, H.J.Z., J.L. and F.Q.; Software, H.J.Z., J.L. and F.Q.; Validation, H.J.Z. and J.L.; writing original draft, H.J.Z., J.L. and F.Q.; review and editing, H.J.Z., J.L. and F.Q.; Funding acquisition, F.Q. All authors have read and agreed to the published version of the manuscript.

Funding: This research was funded by the National Social Science Fund of China, grant number: $17 \mathrm{BSH} 137$.

Institutional Review Board Statement: The study was conducted according to the guidelines of the Declaration of Helsinki and approved by the Institutional Review Board (or Ethics Committee) of Georgia State University (H21264; 18 November 2020).

Informed Consent Statement: Informed consent was obtained from all subjects involved in the study.

Data Availability Statement: Data is not publicly available.

Conflicts of Interest: The authors declare no conflict of interest.

\section{References}

1. National Bureau of Statistics. Statistical Bulletin of the People's Republic of China on National Economic and Social Development 2019. Available online: http://www.stats.gov.cn/tjsj/zxfb/202002/t20200228_1728913.html (accessed on 3 August 2021).

2. Gao, Q.; Yang, S.; Li, S. Labor contracts and social insurance participation among migrant workers in China. China Econ. Rev. 2012, 23, 1195-1205. [CrossRef]

3. Wu, W.; Wang, H. As Immigrant in Metropolis: The analysis on housing condition of the floating population in Beijing and Shanghai. Sociol. Res. 2002, 3, 92-110.

4. Wang, Y.P.; Wang, Y.; Wu, J. Housing migrant workers in rapidly urbanizing regions: A study of the Chinese model in Shenzhen. Hous. Stud. 2010, 25, 83-100. [CrossRef]

5. Zhang, Q. Occupational injury occurrence and related risk factors among Chinese migrant workers. Procedia Eng. 2012, 43, 76-81. [CrossRef]

6. Zhu, Y.; Chen, P.Y.; Zhao, W. Injured workers in China: Injustice, conflict and social unrest. Int. Labor Rev. 2014, 153, 635-647. [CrossRef]

7. State Council. Decision about Improving Healthcare in Rural China. 2002. Available online: http://www.gov.cn/gongbao/ content/2002/content_61818.htm (accessed on 3 August 2021).

8. National Bureau of Statistics. Statistical Bulletin of the People's Republic of China on National Economic and Social Development. 2013. Available online: http://www.stats.gov.cn/tjsj/zxfb/201402/t20140224_514970.html (accessed on 3 August 2021). 
9. Cohen, M. TH Marshall's “citizenship and social class". Dissent 2010, 57, 81-85. [CrossRef]

10. Vollaard, H.; Martinsen, D.S. The rise of a European healthcare union. Comp. Eur. Politics 2017, 15, 337-351. [CrossRef]

11. Mossialos, E.; Baeten, R.; Permanand, G.; Hervey, T.K. Health systems governance in Europe: The role of European Union law and policy. In Health Systems Governance in Europe; Mossialos, E., Baeten, R., Permanand, G., Hervey, T.K., Eds.; Cambridge University Press: Cambridge, MA, USA, 2010; pp. 1-83. [CrossRef]

12. Ge, C.; Huang, S. Challenges in innovation and implementation of harmonious core value and countermeasures. J. Hohai Univ. Philos. Soc. Sci. 2017, 19, 17-23.

13. Qiu, Z. Re-exploration of rural revitalization and the relationship between urban and rural areas: How can people's livelihood be improved. Res. Soc. Dev. 2020, 7, 1-16.

14. Wang, L.; Wang, A.; FitzGerald, G.; Si, L.; Jiang, Q.; Ye, D. Who benefited from the new rural cooperative medical system in China? A case study on Anhui Province. BMC Health Serv. Res. 2016, 16, 195. [CrossRef]

15. Zhao, M.; Miao, Y. The review and prospect of the primary health care system development over the past 70 years since the founding of China. Chin. J. Health Policy. 2019, 12, 10-15.

16. Carrin, G.; Ron, A.; Hui, Y.; Hong, W.; Tuohong, Z.; Licheng, Z.; Xuesheng, L. The reform of the rural cooperative medical system in the People's Republic of China: Interim experience in 14 pilot counties. Soc. Sci. Med. 1999, 48, 961-972. [CrossRef]

17. Ling, M. An analysis of Chinese rural cooperative medical service system from public policy perspective. Jianghai Acad. J. 2002, 3, 91-96.

18. Zhang, G.L.; Zhang, X.W. Strategies for solving the NCMS fee collection dilemma under the background of targeted poverty alleviation-A case study based on B town in southern Guangxi. J. Nanjing Agric. Univ. 2018, 18, 45-56.

19. Taihe County Government. Basic Medical Insurance Policies for Urban and Rural Residents in Anhui Province. 2020. Available online: http:/ / www.taihe.gov.cn/openness/detail/5fac979a7f8b9a9b0d8b4576.html (accessed on 3 August 2021).

20. Wang, H.M.; Gao, H.; Li, H.; Li, Z. The role of government in China's rural health security system. J. Pekin Univ. 2003, 40, 128-134.

21. Zhou, X.G.; Lu, M. The rural migrant workers health: China s success or regret? China J. Econ. 2016, 3, 79-98.

22. State Council. The Integration of China's Urban and Rural Healthcare System. 2016. Available online: http://www.gov.cn/ zhengce/content/2016-01/12/content_10582.htm (accessed on 3 August 2021).

23. Zhang, J. The institutional root of the slow development of the NRCMIS. Rural. Econ. 2009, 401, 80-84.

24. Hua, N.; Chen, S. The impact of the variation of the NRCMIS on the flow of rural laborers. R J. Party Sch. CPC Zhengzhou Munic. Comm. 2018, 3, 46-48.

25. Cheng, Z.; Nielsen, I.; Smyth, R. Access to social insurance in urban China: A comparative study of rural-urban and urban-urban migrants in Beijing. Habitat Int. 2014, 41, 243-252. [CrossRef]

26. Song, L.; Qi, T.G. Analysis on the causes of low labor contracting rate of migrant workers in China-The analytical framework based on labor market segmentation and industry segmentation. East China Econ. Manag. 2014, 28, 34-40.

27. Idler, E.L.; Hudson, S.V.; Leventhal, H. The meanings of self-ratings of health: A qualitative and quantitative approach. Res. Aging 1999, 21, 458-476. [CrossRef]

28. Ma, C.; Qu, Z.; Xu, Z. Internal migration and mental health: An examination of the healthy migration phenomenon in China. Popul. Res. Policy Rev. 2020, 39, 493-517. [CrossRef]

29. Haseli-Mashhadi, N.; Pan, A.; Ye, X.; Wang, J.; Qi, Q.; Liu, Y.; Li, H.; Yu, Z.; Lin, X.; Franco, O.H. Self-rated health in middle-aged and elderly Chinese: Distribution, determinants, and associations with cardio-metabolic risk factors. BMC Public Health 2009, 9, 368. [CrossRef]

30. Yang, H.; He, F.; Wang, T.; Liu, Y.; Shen, Y.; Gong, J.; Dai, W.; Zhou, J.; Gu, J.; Tu, Y. Health-related lifestyle behaviors among male and female rural-to-urban migrant workers in Shanghai, China. PLoS ONE 2015, 10, e0117946. [CrossRef]

31. Wong, K.D.F.; Li, C.Y.; Song, H.X. Rural migrant workers in urban China: Living a marginalized life. Int. J. Soc. Welf. 2007, 16, 32-40. [CrossRef]

32. Yang, C. The influence of income and working time of rural migrant workers on health: The mediating effect of life stress and the moderating effect of marital status. Hum. Syst. Manag. 2020, 39, 69-80. [CrossRef]

33. Meng, F.; Li, Z. A study on the influence of urban integration on the physical health of rural migrant workers. J. Ocean Univ. China 2019, 4, 104-113.

34. Liu, L.; Zhang, X.; Zhao, L. Empirical analysis of the status and influencing factors of catastrophic health expenditure of migrant workers in western China. Int. J. Environ. Res. Public Health 2019, 16, 738. [CrossRef]

35. Liu, S.; Griffiths, S.M. From economic development to public health improvement: China faces equity challenges. Public Health 2011, 125, 669-674. [CrossRef]

36. Zhang, X.; Yu, B.; He, T.; Wang, P. Status and determinants of health services utilization among elderly migrants in China. Glob. Health Res. Policy 2018, 3, 1. [CrossRef]

37. Du, H. A Survey of Rural Floating Population; Academic Press: Cambridge, MA, USA, 2015.

38. Zheng, G.; Huang, L. Rural-Urban Migrant Workers in China: Issue and Social Protection; Renmin Press: Beijing, China, 2007.

39. Strauss, A.; Corbin, J. Basic of Qualitative Research Techniques; Sage: Thousand Oaks, CA, USA, 1998.

40. Qiu, F.; Zhan, H.J.; Liu, J.; Barrentt, P.M. Downward transfer of support and care: Understanding the cultural lag in rural China. Ageing Soc. 2020, 1-26. [CrossRef] 
41. Jiang, C. Gender role concept, family care and migrant women's labor participation: An empirical research based on CGSS 2015. J. Hebei Agric. Univ. 2021, 23, 109-115.

42. Pan, Y. Building a welfare system with Chinese characteristics: From a residual type to moderate universalism. In Aging Welfare and Social Policy_China and the Nordic Countries in Comparative Perspectives; Jing, K., Stein, Y.P., Chen, S., Eds.; Springer: Amsterdam, The Netherlands, 2019; pp. 15-29.

43. World Data Atlas 2020. China's Gini Index in 2018. Available online: https://knoema.com/atlas/China/topics/Poverty/IncomeInequality/GINI-index (accessed on 3 August 2021). 